\title{
Oxycodone/naloxone as a therapeutic option in a patient with chronic pain and opioid-induced bowel dysfunction
}

\author{
Leszek Kraj ${ }^{1,2}$, Joanna Krawczyk ${ }^{1}$ \\ ${ }^{1}$ Department of Haematology, Oncology and Internal Diseases, Medical University of Warsaw, Poland \\ ${ }^{2}$ Department of Biochemistry, Medical University of Warsaw, Poland
}

Contemp Oncol (Pozn) 2014; 18 (3): 215-217 DOI: $10.5114 /$ wo.2014.43902

Cancer-induced pain is a complex issue of utmost importance in everyday clinical practice. Published data show that the majority of patients with advanced or disseminated cancer and between $27 \%$ and $60 \%$ of ambulatory cancer patients in various stages of the disease may suffer from moderate or severe pain (VAS 5-10) [1, 2].

However, it has been demonstrated that up to $82 \%$ of patients with cancer-induced pain may be inadequately treated, with postponed introduction of WHO analgesic ladder third-level drugs in a substantial subset of this population [3, 4]. Unfortunately, ineffectively controlled pain is associated with high risk of unfavourable psychosomatic consequences.

Concern about undesirable effects of potent opioids is undoubtedly one of the main causes of inadequate analgesic treatment as almost $80 \%$ of patients experience at least one side effect [5]. Opioids' side effects are typically mild in intensity and not life-threatening, but they may significantly impair the quality of life.

One of the most important clinical issues in this regard is opioid-induced bowel dysfunction (OIBD). OIBD is mainly manifested by persistent constipation, which is the most frequent undesirable effect of regimens containing opioid analgesics $[6,7]$. In a subset of patients the severity of constipation may cause unacceptable decline of the quality of life, despite appropriate laxative treatment or prevention.

Thus, a treatment strategy combining effective analgesia with concomitant maintenance or recovery of proper bowel function should be an attractive option for this patient group. Currently, this goal may be achieved by combined administration of oxycodone with naloxone, with pharmaceutical products containing both these agents in a $2: 1$ ratio, marketed as prolonged-release (PR) tablets.

Oxycodone is a potent opioid analgesic agent belonging to the third rung of the WHO analgesic ladder. It is characterized by high bioavailability after oral administration (up to 87\%) and wide distribution in all body compartments. It shows $45 \%$ binding to serum proteins, whereas the serum half-life varies between 3 and 5 hours. The drug is metabolized in the liver via the P-450 cyto- chrome system (CYP3A4, CYP2D6) into active metabolites, which do not play a dominant role in drug pharmacodynamics due to low serum concentrations. Elimination of the drug occurs via urine and faeces, while moderate or severe liver or renal insufficiency increases the exposure [8-10].

Oxycodone may be especially efficacious in the treatment of visceral pain, as well as in the elderly, due to lower frequency of cognitive impairment. While changing morphine to oxycodone, the dosing should be recalculated using a conversion rate of $2: 1$ or $1.5: 1$ (according to the manufacturer and Palliative Care Formulary, respectively) $[9,11]$.

On the other hand, naloxone is a semisynthetic morphine derivative acting as a competitive, pure opioid receptor antagonist. It is characterized by very low bioavailability after oral administration $(<3 \%)$ and rapid liver metabolism into inactive compounds ("first pass effect"), with no measurable systemic effects after oral intake.

Therefore, only parenteral administration of naloxone may antagonize systemic effects of opioid treatment, including their analgesic action. However, naloxone taken via the oral route exerts its action only locally, blocking opioid receptors in the intestinal wall and counteracting the opioid-induced bowel dysfunction.

It has been show that oral naloxone improves intestinal motor function, prevents constipation and allows for reduction of laxative agents' consumption during opioid-based analgesic treatment. Simultaneously, their analgesic efficacy remained uninfluenced [10-13]. Thus, it may be a valuable option of pain management in palliative medicine patients with constipation [14].

The concept to combine these two active agents, namely a potent opioid receptor agonist with a competitive opioid antagonist with different pharmacokinetic properties, enables preservation of full analgesic action with concomitant neutralization of the negative impact on bowel motility.

The efficacy of oxycodone/naloxone PR tablets in cancer patients has been confirmed in the double-blinded placebo-controlled randomized clinical study OXN2001. 
The study measured the influence of this drug combination on bowel function assessed by Bowel Function Index $(\mathrm{BFI})$ and on pain control. The control arm comprised patients receiving oxycodone PR without naloxone. After 4-week treatment, the study showed that oxycodone/naloxone PR tablets significantly improved bowel function with a decrease of constipation severity, without compromising pain control and drug safety, in comparison to oxycodone PR [15].

Similar conclusions can be drawn from a large observational study encompassing over a thousand patients with cancer-induced pain, where oxycodone/naloxone PR tablets showed a favourable influence on bowel function with preservation of high analgesic efficacy [16]. The study also confirmed good tolerance of the drug.

Data mentioned above are also consistent with the results of studies (OXN3001, OXN3006, OXN3401) conducted in patients with moderate or severe non-cancer pain. Improvement of intestinal motility with simultaneous preservation of analgesic activity and good treatment tolerability after combined administration of oxycodone and naloxone in PR tablets was also confirmed in these patient groups [17-19].

A 78-year-old man was referred to the Outpatient Palliative Care Unit because of severe cancer pain assessed as $6 / 10$ on a numeric rating scale (NRS). Nine months earlier the patient had been diagnosed with unresectable and metastatic bladder cancer. He had been treated by palliative chemotherapy with no response. The patient described the pain as dull, chronic and located mainly in the lower abdomen. Additionally, the patient suffered from nausea, fatigue and loss of appetite. Despite the treatment with tramadol (200 mg/day), paracetamol (2 g/ day) and ketoprofen (100 mg/day), the pain intensified as the cancer progressed. After oral titration, oral morphine $60 \mathrm{mg} /$ day was administered. At this dosage, the patient obtained good pain control (NRS 2/10). After one week, despite being prescribed combined softener (liquid paraffin, $20 \mathrm{ml} / 48 \mathrm{~h}$ ) and stimulant laxatives (senna, 1 tabl./12 h and glycerol suppositories) for the prevention of OIBD, severe constipation occurred. Only lactulose (15 ml/12 h) brought a transient minor improvement, but it caused unpleasant side effects such as abdominal colic and bloating. As a result, the oral form of morphine was replaced with a transdermal formulation of fentanyl $(50 \mu \mathrm{m} / \mathrm{h})$ which controlled the pain but still caused severe constipation. Opioid dose reduction led to recurrence of severe pain. Overall, transdermal fentanyl was used for 7 weeks. Thereafter, the patient was switched to oral oxycodone/ naloxone PR (20 mg oxycodone + 10 naloxone/day). This relatively low dosage (maximum recommended dosage of oxycodone/naloxone PR is $80 \mathrm{mg} / 40 \mathrm{mg}$ ) brought an improvement of pain control as well as remission of constipation. There were no serious side effects noted and the tolerance of the treatment was good.

Taking into consideration the specific properties and mechanism of action, as well as results of studies showing its clinical efficacy, it should be concluded that treatment with combined oxycodone/naloxone PR tablets is a valuable treatment option in pain management. The greatest benefit may be achieved in patients with a baseline predisposition to constipation or opioid-induced bowel dysfunction, which was confirmed in the case described above.

\section{References}

1. Hearn J, Higginson IJ. Cancer pain epidemiology: a systematic review Cancer Pain, Assessment and Management 2003. Bruera ED, Portenoy RK (eds.). Cambridge University Press, Cambridge 2003.

2. TeBoveldt N, Vernooij-Dassen M, Burger N, ljsseldijk M, Vissers K, Engels Y. Pain and its interference with daily activities in medical oncology outpatients. Pain Physician 2013; 16: 379-89.

3. Deandrea S, Montanari M, Moja L, Apolone G. Prevalence of undertreatment in cancer pain. A review of published literature. Ann Oncol 2008; 19: 1985-91.

4. Apolone G, Corli O, Caraceni A, Negri E, Deandrea S, Montanari M, Greco MT; Cancer Pain Outcome Research Study Group (CPOR SG) Investigators. Pattern and quality of care of cancer pain management. Results from the Cancer Pain Outcome Research Study Group.Br J Cancer 2009; 100: 1566-74.

5. http://www.britishpainsociety.org/book_opioid_main.pdf.

6. Sharma A, Jamal MM. Opioid induced bowel disease: a twenty-first century physicians' dilemma. Considering pathophysiology and treatment strategies. Curr Gastroenterol Rep 2013; 15: 334.

7. Pappagallo M. Incidence, prevalence, and management of opioid bowel dysfunction. Am J Surg 2001; 182 (5A Suppl): 11S-18S.

8. Lugo RA, Kern SE. The pharmacokinetics of oxycodone. J Pain Palliat Care Pharmacother 2004; 18: 17-30.

9. Ordóñez Gallego A, González Barón M, Espinosa Arranz E. Oxycodone: a pharmacological and clinical review. Clin Trans Oncol 2007; 9: 298-307.

10. Burness CB, Keating GM. Oxycodone/Naloxone prolonged-release: a review of its use in the management of chronic pain while counteracting opioid-induced constipation. Drugs 2014; 74 : 353-75.

11. http://www.medicines.ie/medicine/14383/SPC/Targin\%2b$10 \mathrm{mg} \% 2 \mathrm{~b} 5 \mathrm{mg} \% 2$ band\%2b20mg\%2b10mg\%2bprolonged $\% 2$ bre lease\%2btablets/\#POSOLOGY.

12. Barnett V, Twycross R, Mihalyo M, Wilcock A. Opioid antagonists. J Pain Symptom Manage 2014; 47: 341-52.

13. Smith K, Hopp M, Mundin G, Bond S, Bailey P, Woodward J, Bell D. Low absolute bioavailability of oral naloxone in healthy subjects. Int J Clin Pharmacol Ther 2012; 50: 360-7.

14. Leppert W, Dzierżanowski T, Ciałkowska-Rysz A, Jarosz J, Pyszkowska J, Stachowiak A. Postępowanie u chorych z zaparciem stolca w medycynie paliatywnej - zalecenia Grupy Roboczej Ekspertów Polskiego Towarzystwa Medycyny Paliatywnej. Medycyna Paliatywna 2009; 1: 1-10.

15. AhmedzaiSH, Nauck F, Bar-Sela G, Bosse B, LeyendeckerP,Hopp M. A randomized, double-blind, active-controlled, double-dummy, parallel-group study to determine the safety and efficacy of oxycodone/naloxone prolonged-release tablets in patients with moderate/severe, chronic cancer pain. Palliat Med 2012; 26: $50-60$.

16. Nolte T, Schutter U, Loewenstein O. Cancer pain therapy with a fixed combination of prolonged-release oxycodone/naloxone: results from a non-interventional study. Pragmat Obs Res 2013. http:// www.dovepress.com/cancer-pain-therapy-with-a-fixed-combination-of-prolonged-release-oxyc-peer-reviewed-article-POR.

17. Simpson K, Leyendecker P, Hopp M, Müller-Lissner S, Löwenstein O, De Andrés J, Troy Ferrarons J, Bosse B, Krain B, Nichols T, Kremers W, Reimer K. Fixed-ratio combination oxycodone/naloxone compared with oxycodone alone for the relief of opioid-induced constipation in moderate-to-severe noncancer pain. Curr Med Res Opin 2008; 24: 3503-12.

18. Löwenstein O, Leyendecker P, Hopp M, Schutter U, Rogers PD, Uhl R, Bond S, Kremers W, Nichols T, Krain B, Reimer K. Combined prolonged-release oxycodone and naloxone improves bowel function in patients receiving opioids for moderate-to-severe 
non-malignant chronic pain: a randomised controlled trial. Expert Opin Pharmacother 2009; 10: 531-43.

19. Vondrackova D, Leyendecker P, Meissner W, Hopp M, Szombati I, Hermanns K, Ruckes C, Weber S, Grothe B, Fleischer W, Reimer K. Analgesic efficacy and safety of oxycodone in combination with naloxone as prolonged release tablets in patients with moderate to severe chronic pain. J Pain 2008; 9: 1144-54.

\section{Address for correspondence}

\section{Leszek Kraj}

Department of Haematology, Oncology and Internal Diseases

Medical University of Warsaw

Banacha $1 \mathrm{~A}$

02-097 Warsaw, Poland

e-mail: leszekkraj@gmail.com

Submitted: 2.06 .2014

Accepted: $\quad 15.06 .2014$ 